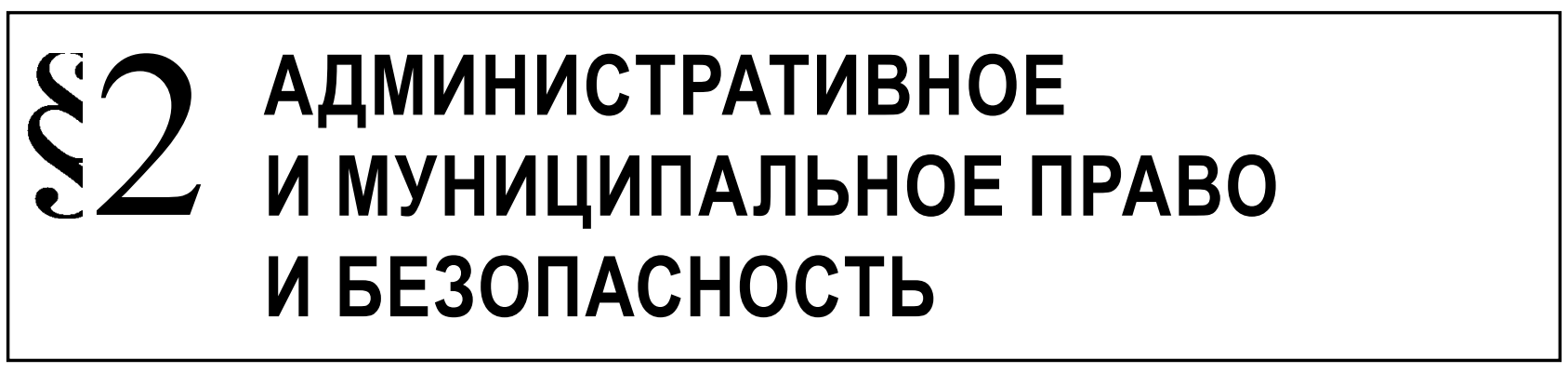

Купреев С.С.

\title{
АДМИНИСТРАТИВНОЕ ПРАВО НА СТРАЖЕ ГОСУДАРСТВЕННОЙ БЕЗОПАСНОСТИ
}

\begin{abstract}
Аннотация: Статья посвящена роли и значению административного права в обеспечении государственной безопасности. Для норм административного права характерна ярко выраженная предупредительная направленность, а с учетом того, что приоритет предупредительных мер является одним из основных принципов обеспечения безопасности, применение мер административно-правового воздействия способно обеспечивать значительный эффект в сфере обеспечения государственной безопасности. Повышение уровня административно-правового обеспечения государственной безопасности иллюстрируется такими примерами, как совершенствование законодательства о государственной службе, о деятельности иностранных неправительственных организаций и организаций с иностранным финансированием, усилением регламентации организации и проведения публичных мероприятий. Отдельное внимание в статье уделено вопросам административной деятельности российских специальных служб. Статья подготовлена на основе изучения нормативных правовых актов и правоприменительной практики в срере обеспечения государственной безопасности, а также с использованием исторического и сравнительного методов научного исследования. В статье на основе анализа различных аспектов использования административно-правового инструментария в сфере обеспечения государственной безопасности делается вывод о безусловном усилении роли административного права в данной сфере и о необходимости дальнейшего совершенствования административного законодательства, регулирующего рассматриваемые вопросы. При этом применение мер административного воздействия должно отвечать не только принципам законности и соблюдения прав человека, но и принципу целесообразности принимаемых решений.

Ключевые слова: административное право, государственная безопасность, административная деятельность, государственная служба, иностранные организации, публичные мероприятия, противодействие терроризму, профилактика, предупредительная деятельность, спеислужбы.
\end{abstract}

$\mathrm{B}$ условиях нарастания международной напряженности, террористической активности, других угроз внешнего и внутреннего характера $^{1}$ все больше внимания в нашей стране уделяется вопросам государственной безопасности, то есть защите конституционного строя, государственных органов, обеспечения территориальной целостности и суверенитета государства. Основная роль в обеспечении государственной безопасности безусловно отводится деятельности специальных

1 Подробнее об этом см.: Стратегия национальной безопасности Российской Федерации до 2020 года, утвержденная Указом Президента РФ от 12 мая 2009 г. N 537. служб и правоохранительных органов, осуществляемой как гласными, так и негласными методами. Большой потенциал в данной сфере заложен также в применении общегосударственных правовых мер и в том числе административно-правового инструментария. Для норм административного права характерна ярко выраженная предупредительная направленность, а с учетом того, что приоритет предупредительных мер является одним из основных принципов обеспечения безопасности늘

См. ст. 2 Федерального закона от 28 декабря 2010 г. № 390Ф3 «О безопасности». 
го воздействия способно обеспечивать значительный эффект в сфере обеспечения государственной безопасности. В предыдущие несколько лет уровень административно-правового обеспечения государственной безопасности был существенно повышен, причем не столько за счет развития институтов защиты государственной тайны и охраны государственной границы, как путем принятия дополнительных организационно-правовых мер в ряде других сфер общественной жизни, ранее непосредственно не связанных с обеспечением государственной безопасности. Указанный тезис может быть проиллюстрирован несколькими конкретными примерами.

Совершенствование законодательства о государственной службе. Одним из инструментов обеспечения безопасности государственных органов является установление оптимального правового статуса государственных служащих, обладание которым позволяет им максимально эффективно осуществлять свою профессиональную служебную деятельность и не подвергаться при этом какому-либо неправомерному воздействию со стороны внешних субъектов. Наделяя государственных служащих полномочиями, гарантируя им материальное обеспечение их деятельности и меры социальной поддержки, государство вынуждено устанавливать для них определенные ограничения и запреты, обеспечивающие максимальное снижение их уязвимости от внешних факторов. Таковы, например, запреты иметь гражданство иного государства, заниматься предпринимательской деятельностью, получать в связи с исполнением должностных обязанностей вознаграждения от физических и юридических лиц ${ }^{3}$, обязанности и ограничения, установленные антикоррупционным законодательством. С 2013 г. для отдельных категорий лиц установлен запрет открывать и иметь счета (вклады), хранить наличные денежные средства и ценности в иностранных банках, расположенных за пределами территории Российской Федерации, владеть и (или) пользоваться иностранными финансовыми инструментами ${ }^{4}$. В

\footnotetext{
3 См. ст. 16, 17 Федерального закона от 27 июля 2004 г. № 79-Ф3 «О государственной гражданской службе Российской Федерации».

4 Федеральный закон от 7 мая 2013 г. № 79-Ф3 «О запрете отдельным категориям лиц открывать и иметь счета (вклады), хранить наличные денежные средства и ценности в иностранных банках, расположенных за пределами территории Российской Федерации, владеть и (или) пользоваться иностранными финансовыми инструментами».
}

отношении государственных служащих, имеющих непосредственное отношение к обеспечению государственной безопасности, предусматриваются еще более обширный перечень ограничений и запретов: им не разрешается иметь вид на жительство или иные документы, подтверждающие право на постоянное проживание на территории иностранного государства, зарегистрированное за пределами Российской Федерации право собственности на имуществ ${ }^{5}$. Ограничения распространяются даже на выезд за границу 6 . Указанная совокупность ограничений и запретов, предусмотренных для российских государственных служащих, хотя и создает для них определенные неудобства, в то же время вызвана объективной необходимостью и позволяет обеспечить их безопасность и независимость в условиях возрастающей международной напряженности.

Совершенствование законодательства о деятельности иностранных некоммерческих организаций и организаций с иностранным финансированием. На территории России действует большое количество иностранных некоммерческих организаций, осуществляющих правозащитные, благотворительные и иные социально значимые функции. В целях недопущения использования таких организаций в противоправной (в том числе террористической) деятельности, наносящей ущерб безопасности государства, начиная с 2006 г. был принят ряд законодательных мер ${ }^{7}$, направленных на четкое закрепление порядка их функционирования, а также на установление их юридической ответственности за нарушение российского законодательства. В Федеральном законе «0 некоммерческих организациях» ${ }^{8}$ появилось понятие иностранной некоммерческой неправительственной организации (ИННО), установлены правила создания и деятельности структурных подразделений ИННО на территории России. Иностранной организации может быть отказано в открытии структурного подразделения, если цели и задачи его созда-

\footnotetext{
См. ст. 16 Федерального закона от 3 апреля 1995 г. № 40Ф3 «О федеральной службе безопасности».

6 См. ст. 15 Федерального закона от 15 августа 1996 г. № 114Ф3 «О порядке выезда из Российской Федерации и въезда в Российскую Федерацию».

7 См. Федеральный закон от 10 января 2006 г. № 18-Ф3 «О внесении изменений в некоторые законодательные акты Российской Федерации».

8 Федеральный закон от 12 января 1996 г. № 7-Ф3 «О некоммерческих организациях».
} 
ния противоречат российскому законодательству или создают угрозу суверенитету, политической независимости, территориальной неприкосновенности и национальным интересам Российской Федерации. Каждое структурное подразделение ИННО обязано информировать российские административные власти об объеме получаемых денежных средств и иного имущества, их предполагаемом распределении, о целях их расходования (использования) и об их фактическом расходовании (использовании). В случае несоответствия деятельности подразделения ИННО заявленным целям и задачам или невыполнения установленных законом требований соответствующее структурное подразделение может быть закрыто.

В 2012 г. в законодательстве ${ }^{9}$ появилось понятие некоммерческой организации, выполняющей функции иностранного агента, т.е. российской организации, получающей финансирование из зарубежных источников и занимающейся политической деятельностью10. Подобные организации вносятся в соответствующий реестр, представляют в уполномоченный орган документы, содержащие отчет о своей деятельности, о персональном составе руководящих органов, о целях расходования денежных средств и использования иного имущества. За нарушение установленных правил деятельности деятельность организации приостанавливается, возможно привлечение организации и ее должностных лиц к административ-

\footnotetext{
9 Федеральный закон от 20 июля 2012 г. № 121-Ф3 «О внесении изменений в отдельные законодательные акты Российской Федерации в части регулирования деятельности некоммерческих организаций, выполняющих функции иностранного агента».

10 Некоммерческая организация, за исключением политической партии, признается участвующей в политической деятельности, осуществляемой на территории Российской Федерации, если независимо от целей и задач, указанных в ее учредительных документах, она участвует (в том числе путем финансирования) в организации и проведении политических акций в целях воздействия на принятие государственными органами решений, направленных на изменение проводимой ими государственной политики, а также в формировании общественного мнения в указанных целях.

К политической деятельности не относится деятельность в области науки, культуры, искусства, здравоохранения, профилактики и охраны здоровья граждан, социальной поддержки и защиты граждан, защиты материнства и детства, социальной поддержки инвалидов, пропаганды здорового образа жизни, физической культуры и спорта, защиты растительного и животного мира, благотворительная деятельность, а также деятельность в области содействия благотворительности и добровольчества.
}

ной ответственности ${ }^{11}$. Минюст России ежегодно представляет Государственной Думе Федерального Собрания Российской Федерации доклад о деятельности некоммерческих организаций, выполняющих функции иностранного агента, содержащий информацию об участии их в политической деятельности, осуществляемой на территории России, о поступлении и расходовании денежных средств, а также о результатах контроля за их деятельностью.

Регламентация организации и проведения публичных мероприятий. События, происходившие в столице Украины в конце 2013 - начале 2014 г., доказали важность детальной регламентации организации и проведения собраний, митингов и других публичных мероприятий в целях недопущения их перерастания в массовые беспорядки. В России еще с 2004 г. действует Федеральный закон «0 собраниях, митингах, демонстрациях, шествиях и пикетированиях», устанавливающий порядок реализации гражданами предоставленного им Конституцией РФ права собираться мирно, без оружия и проводить публичные мероприятия. В 2012 г. указанный Федеральный закон был дополнен целым рядом норм ${ }^{12}$, касающихся порядка подготовки и проведения публичного мероприятия, а также статуса организаторов и участников соответствующих мероприятий. Так, в частности, участникам публичных мероприятий было запрещено скрывать свое лицо, в том числе использовать маски, средства маскировки, иные предметы, специально предназначенные для затруднения установления личности, иметь при себе оружие или предметы, используемые в качестве оружия, взрывчатые и легковоспламеняющиеся вещества. За несоблюдение требований законодательства о проведении публичных мероприятий оптимизирована административная ответственность, в качестве альтернативы административному аресту установлен новый вид административного наказания - обязательные работы ${ }^{13}$. Необходимо констатировать,

\footnotetext{
11 См. статьи 19.75-2, 19.34, 20.28 Кодекса Российской Федерации об административных правонарушениях.

12 См. Федеральный закон от 8 июня 2012 г. № 65-Ф3 «О внесении изменений в Кодекс Российской Федерации об административных правонарушениях и Федеральный закон «О собраниях, митингах, демонстрациях, шествиях и пикетированиях».

13 Подробнее об этом см.: Купреев С. С. Обязательные работы как новый вид административного наказания // Полицейская деятельность. 2013. № 1.
} 
что указанные законодательные нововведения несмотря на присущий им ограничительный характер вполне соответствуют общемировой практике, которая зачастую является гораздо более жесткой и связана с широким применением уголовной ответственности за нарушение установленных правил. Закрепленная Конституцией РФ свобода собраний безусловно не означает вседозволенность $^{14}$, а пользование данной свободой не должно нарушать законных интересов третьих лиц и всего общества.

Подвергается совершенствованию и законодательство, регулирующее административную деятельность спецслужб. Здесь также можно привести несколько примеров.

Применение мер профилактики. Как в свое время писал один из классиков юридической науки Чезаре Беккариа, «лучше предупреждать преступления, чем наказывать. В этом - главная цель всякого хорошего законодательства...» ${ }^{15}$. Для реализации указанной цели в 2010 г. в России на законодательном уровне был воссоздан институт профилактики в сфере обеспечения государственной безопасности, в основе которой лежат меры административного предупреждения ${ }^{16}$. Статья $13^{1}$ Федерального закона «0 федеральной службе безопасности» предусматривает две меры профилактики, применяемые органами федеральной службы безопасности: внесение представления об устранении причин и условий, способствующих реализации угроз безопасности Российской Федерации и объявление официального предостережения о недопустимости действий, создающих условия для совершения преступлений, дознание и предварительное следствие по которым отнесено законодательством Российской Федерации к ведению органов федеральной службы безопасности.

Согласно пункту «л)» статьи 13 Федерального закона «О федеральной службе безопасно-

\footnotetext{
14 «Права на свободу слова и собраний, являясь фундаментальными для нашего демократического общества, тем не менее, не означают, что каждый, кто желает выразить свое мнение или идеи, может сделать это публично в любом общественном месте или же в любое время» (Решение Верховного Суда США по делу «Кокс против штата Луизиана», 379 U.S. 536 (1965), стр.554).

15 Беккариа Ч. О преступлениях и наказаниях. М.: Инфра-М, 2011. С. 150.

16 См. Федеральный закон от 27 июля 2010 г. № 238-Ф3 «О внесении изменений в Федеральный закон «О федеральной службе безопасности» и в Кодекс Российской Федерации об административных правонарушениях».
}

сти» органы федеральной службы безопасности вправе вносить в государственные органы, администрации предприятий, учреждений и организаций независимо от форм собственности, а также в общественные объединения обязательные для исполнения представления об устранении причин и условий, способствующих реализации угроз безопасности Российской Федерации, совершению преступлений, дознание и предварительное следствие по которым отнесены законодательством к их ведению ${ }^{17}$. Внесение указанных представлений осуществляется при наличии достаточных данных, выявленных в процессе оперативно-служебной деятельности органов безопасности и указывающих на наличие причин и условий, способствующих реализации угроз безопасности государства ${ }^{18}$, имеет значительное профилактическое действие, позволяет своевременно предотвратить совершение преступлений, связанных с нанесением ущерба интересам государственной безопасности. Для повышения эффективности применения данной меры представляется необходимым четко установить на законодательном уровне конкретную ответственность должностных лиц организаций, в которые вносятся представления, за необоснованное неисполнение содержащихся в представлении предписаний ${ }^{19}$.

Пунктом «г.2)» статьи 13 Федерального закона «0 федеральной службе безопасности» органам федеральной службы безопасности предоставлено право объявления обязательного для исполнения официального предостережения о недопустимости действий, создающих условия для совершения преступлений, дознание и предварительное следствие по которым отнесено к ведению органов безопасности, при отсутствии оснований для привлечения к уголовной ответственности. Объявление официального предостережения физическим лицам составляет институт индивидуальной профилактики, активно применявшийся органами го-

\footnotetext{
17 Порядок внесения представлений установлен приказом ФСБ России от 13 марта 2004 г. № 162 «О внесении представлений органами федеральной службы безопасности и пограничными войсками».

18 См. ст. $13^{1}$ Федерального закона «О федеральной службе безопасности».

19 См.: Купреев С. С., Дорофеев Р. О. Административноправовые средства профилактики преступлений, применяемые в сфере обеспечения государственной безопасности // Полицейская деятельность. 2013. № 2. С. 764.
} 
сударственной безопасности в советское время ${ }^{20}$ и возрожденный в 2010 г. Конечно, на сегодняшний день уровень правового регулирования данного института существенно возрос: учетом того, что официальное предостережение непосредственно затрагивает права и свободы граждан, закон закрепляет четкие требования к процедуре ${ }^{21}$ его объявления. Основанием для объявления предостережения должны служить достаточные и предварительно подтвержденные сведения о действиях физического лица, создающих условия для совершения преступлений ${ }^{22}$, объявлению официального предостережения должно предшествовать обязательное уведомление прокурора. Несмотря на то, что воссоздание индивидуальной профилактики в сфере обеспечения государственной безопасности сопровождалось широким общественным резонансом, носившим в целом негативный оттенок, за время своего применения данный институт доказал объективную необходимость своего существования и эффективность, что подтверждается в том числе Общественным советом при ФСБ России ${ }^{23}$.

20 Последнее упоминание о данном институте в советских законодательных актах имело место в Законе СССР от 16 мая 1991 г. № 2159-I «Об органах государственной безопасности в СССР». Необходимо отметить, что после распада СССР в ряде государств-участников СНГ органы государственной безопасности сохранили за собой право объявления предостережения физическим лицам. Подробнее об этом см.: Редкоус В. М. Институт официального предостережения в административной деятельности национальных органов безопасности стран-участниц СНГ // Закон и право. 2010. № 4.

21 Порядок объявления официального предостережения установлен приказом ФСБ России от 2 ноября 2010 г. № 544 «Об объявлении органами федеральной службы безопасности официального предостережения о недопустимости действий, создающих условия для совершения преступлений, дознание и предварительное следствие по которым отнесено законодательством Российской Федерации к ведению органов федеральной службы безопасности».

22 Основанием для объявления официального предостережения являются сведения о конкретных действиях физического лица, создающих условия для совершения преступлений:

проявляющих вовне (словесно, письменно или иным образом) намерения совершить определенное преступление при отсутствии признаков приготовления к преступлению или покушения на преступление;

образующих приготовление к преступлениям небольшой и средней тяжести либо непосредственно направленных на совершение таких преступлений при отсутствии признаков покушения.

23 Информация ФСБ России о практике объявления в 2013 г. официальных предостережений физическим лицам
В мае 2014 г. в законодательство были внесены изменения ${ }^{24}$, касающиеся вопросов противодействия терроризму, согласно которым, в частности, органы федеральной службы безопасности наделены правом проверять у лиц документы, удостоверяющие их личность, осуществлять их личный досмотр и досмотр находящихся при них вещей, если имеются достаточные основания подозревать их в совершении административных правонарушений или преступлений, производство либо дознание или предварительное следствие по которым отнесено законодательством к ведению органов безопасности, а также досмотр транспортных средств и находящихся в них грузов при подозрении, что они используются в целях совершения указанных административных правонарушений или преступлений.

С учетом того, что личный досмотр, досмотр вещей, досмотр транспортного средства являются мерами обеспечения производства по делам об административных правонарушениях и имеют четкую привязку к указанному производству, а их применение связано с ограничением прав и свобод граждан, остается не совсем ясным вопрос о юридической природе предоставленных органам безопасности полномочий: порядок их реализации в законе не закреплен, отсылки к КоАП РФ в законе также нет. Законодателю необходимо определиться, в каком порядке производить указанные действия: либо по правилам КоАП РФ (тогда необходимо делать к нему отсылку) ${ }^{25}$, либо в отдельном порядке (в таком случае необходимо закреплять хотя бы минимальную процедуру их осуществления: реализацию всех действий лицами того же пола, возможно составление протокола либо иного документа). Отсутствие установленного порядка реализации делает обозначенные законодатель-

была заслушана на первом заседании Общественного совета при ФСБ России в 2014 г. Члены Совета отметили, что данная мера профилактики реализуется в строгом соответствии с требованиями законодательства, а ее аккуратное, тщательно выверенное применение позволяет эффективно решать задачи в сфере обеспечения безопасности Российской Федерации, не нарушая при этом баланса интересов государства и прав граждан. См.: Общественный совет при ФСБ России провел первое заседание в 2014 году // ФСБ: За и Против. 2014. № 1. C. 2.

24 См. ст. 1 Федерального закона от 5 мая 2014 г. № 130-Ф3 «О внесении изменений в отдельные законодательные акты Российской Федерации».

25 Подобная привязка существует, к примеру, в Федеральном законе от 7 февраля 2011 г. № 3-Ф3 «О полиции» (см. подп. «16)» п. 1 ст. 13). 
ные новеллы бесполезными, так как в данном случае реализация указанных полномочий едва ли может быть осуществлена без нарушения ряда основополагающих прав человека.

В условиях правового государства применение мер административного воздействия в рассматриваемой сфере должно осуществляться на основе принципов законности, уважения и соблюдения права и свобод человека и гражданина. В то же время, нельзя забывать и о целесообразности принимаемых решений. Как в свое время отмечал А.П. Коренев, «целесообразность в применении норм административного права - это оптимальное достижение цели, сформулированной в норме, в конкретной ситуации... От практической целесообразности, от выбора оптимального варианта решения во многом зависит эффективность применения нормы. Целесообразность означает, что субъект применения нормы обязан максимально учитывать конкретную обстановку, время, место и условия, своеобразие создавшегося положения и т.п.» ${ }^{26}$. В то же время, «о целесообразности в применении норм административного права вне рамок закона не может быть и речи» ${ }^{27}$.

\section{Библиография:}

1. Беккариа Ч. О преступлениях и наказаниях. М.: Инфра-М, 2011.

2. Ирошников Д. В. Правовая политика России в сфере государственной безопасности // Правовая политика в сфере публичного права: проблемы и пути решения : монография. Тамбов: Издательский дом ТГУ им. Г. Р. Державина. 2010.

3. Кардашова И. Б. О проблемах исследования обеспечения национальной безопасности // Административное право и процесс. 2014. № 5.

4. Коренев А.П. Нормы административного права и их применение. М.: Юридическая литература, 1978.

5. Купреев С. С. Обязательные работы как новый вид административного наказания // Полицейская деятельность. 2013. № 1 .

6. Купреев С. С., Дорофеев Р. О. Административно-правовые средства профилактики преступлений, применяемые в сфере обеспечения государственной безопасности // Полицейская деятельность. 2013. № 2.

7. Патрушев Н. П. Особенности современных вызовов и угроз национальной безопасности России // Журнал российского права. 2007. № 7.

8. Правовая основа обеспечения национальной безопасности Российской Федерации : монография / Ю.И. Авдеев, С.В. Аленкин, В.В. Алешин и др.; под ред. А.В. Опалева. М. : ЮНИТИ-ДАНА, 2004.

9. Редкоус В. М. Институт официального предостережения в административной деятельности национальных органов безопасности стран-участниц СНГ // Закон и право. 2010. № 4.

10. Румянцев Н. В. Безопасность как объект государственного управления // Административное право и процесс. 2011. № 7.

11. Куракин А.В., Костенников М.В. Административно-правовое противодействие коррупции в системе государственной службы и в деятельности сотрудников полиции Российской Федерации и зарубежных государств // NB: Российское полицейское право. - 2013. - 1. - C. 65 - 83. DOI: 10.7256/2306-4218.2013.1.735. URL: http://www.enotabene.ru/pm/article_735.html

12. Редкоус В.М. Теоретические проблемы применения института официального предостережения в области обеспечения национальной безопасности // Административное и муниципальное право. - 2013. - 4. - С. 309 - 320. DOI: $10.7256 / 1999-2807.2013 .04 .2$.

\section{References (transliterated):}

1. Bekkaria Ch. O prestupleniyakh i nakazaniyakh. M.: Infra-M, 2011.

2. Iroshnikov D. V. Pravovaya politika Rossii v sfere gosudarstvennoi bezopasnosti // Pravovaya politika v sfere publichnogo prava: problemy i puti resheniya : monografiya. Tambov: Izdatel'skii dom TGU im. G. R. Derzhavina. 2010.

3. Kardashova I. B. O problemakh issledovaniya obespecheniya natsional'noi bezopasnosti // Administrativnoe pravo i protsess. 2014. № 5.

4. Korenev A.P. Normy administrativnogo prava i ikh primenenie. M.: Yuridicheskaya literatura, 1978.

5. Kupreev S. S. Obyazatel'nye raboty kak novyi vid administrativnogo nakazaniya // Politseiskaya deyatel'nost'. 2013 . № 1.

6. Kupreev S. S., Dorofeev R. O. Administrativno-pravovye sredstva profilaktiki prestuplenii, primenyaemye v sfere obespecheniya gosudarstvennoi bezopasnosti // Politseiskaya deyatel'nost'. 2013. № 2.

26 Коренев А.П. Нормы административного права и их применение. М.: Юридическая литература, 1978. С. 67.

27 Там же. С. 69. 


\section{Административное и муниципальное право 10 (82) • 2014}

7. Patrushev N. P. Osobennosti sovremennykh vyzovov i ugroz natsional'noi bezopasnosti Rossii // Zhurnal rossiiskogo prava. 2007. № 7.

8. Pravovaya osnova obespecheniya natsional'noi bezopasnosti Rossiiskoi Federatsii : monografiya / Yu.I. Avdeev, S.V. Alenkin, V.V. Aleshin i dr.; pod red. A.V. Opaleva. M. : YuNITI-DANA, 2004.

9. Redkous V. M. Institut ofitsial'nogo predosterezheniya $\mathrm{v}$ administrativnoi deyatel'nosti natsional'nykh organov bezopasnosti stran-uchastnits SNG // Zakon i pravo. 2010. № 4.

10. Rumyantsev N. V. Bezopasnost' kak ob"ekt gosudarstvennogo upravleniya // Administrativnoe pravo i protsess. 2011 . № 7.

11. Kurakin A.V., Kostennikov M.V. Administrativno-pravovoe protivodeistvie korruptsii v sisteme gosudarstvennoi sluzhby i v deyatel'nosti sotrudnikov politsii Rossiiskoi Federatsii i zarubezhnykh gosudarstv // NB: Rossiiskoe politseiskoe pravo. - 2013. - 1. - C. 65 - 83. DOI: 10.7256/2306-4218.2013.1.735. URL: http://www.e-notabene.ru/pm/article_735.html

12. Redkous V.M. Teoreticheskie problemy primeneniya instituta ofitsial'nogo predosterezheniya $\mathrm{v}$ oblasti obespecheniya natsional'noi bezopasnosti // Administrativnoe i munitsipal'noe pravo. - 2013. - 4. - C. 309 - 320. D0I: 10.7256/19992807.2013.04.2. 